\title{
The way we talk is the way we teach
}

\author{
Curt Tribble, MD, ${ }^{a}$ and Walter H. Merrill, $\mathrm{MD}^{\mathrm{b}}$
}

Our species has existed on this planet for about 200,000 years. We have had some degree of literacy for about 5000 of those years. The printing press has existed for about 500 years. Thus, for the vast majority of the time humans have existed, we have transmitted information orally, mostly through stories. To fail to recognize the value and power of stories is to risk ignoring one of the most potent tools in our teaching armamentarium.

We come from a tradition of storytellers. We both had grandfathers who were born in the late 1800s in rural Alabama. One of them was a southern minister, the other ran a small business. We went to small southern liberal arts colleges, and, despite our inclination toward a career in medicine, we both chose to major in English, perhaps wanting to learn more about our storytelling heritage or perhaps realizing that, by studying communication, we would complement the standard preparation for the discipline of medicine that has often, somewhat erroneously we believe, been categorized as primarily the discipline of human biology.

We have had the privilege to live, work, and teach in our recently adopted state, Mississippi, where the oral traditions of telling stories through music and literature run deep. Very deep. Most American music has its roots in or very near this state, and more Pulitzer Prize winners have come from this state than from any other state in the United States. One of the bestselling authors in the country (John Grisham) is from Mississippi. Thus, we are reminded regularly of the power, the call, of stories. Furthermore, it is apparent to us that not only are the stories important, but it is also true that the storytellers themselves are important. As Marshall McLuhan memorably asserted, "the medium is the message." We ignore this principle to the detriment of our trainees and their future patients.

With all this in mind, we would like to outline some of the principles of using language to transmit the lessons of our discipline to our protégés. We discuss 3 "languages" we believe are important to the practice of medicine and especially important to the teaching and learning of our discipline of cardiothoracic surgery: the language of science, the language of performance, and the language of

\footnotetext{
From the Department of Surgery, ${ }^{a}$ University of Mississippi, Jackson, Miss; and Department of Surgery, ${ }^{\mathrm{b}}$ Vanderbilt University, Nashville, Tenn.

Disclosures: Authors have nothing to disclose with regard to commercial support.

Received for publication Dec 13, 2013; accepted for publication Dec 20, 2013; available ahead of print Jan 31, 2014.

Address for reprints: Curt Tribble, MD, Department of Surgery, University of

Mississippi, Jackson, MI (E-mail: ctribble@umc.edu).

J Thorac Cardiovasc Surg 2014;147:1155-9

$0022-5223 / \$ 36.00$

Copyright (c) 2014 by The American Association for Thoracic Surgery

http://dx.doi.org/10.1016/j.jtcvs.2013.12.025
}

memory. The aspects of the language of science we touch on include the need for precision-balanced by the need for the freedom to doubt. In discussing the language of performance, we touch on leadership, optimism, and reflection. Finally, we address the use of enthusiasm, stories, and conversations to enhance the ability of our trainees to remember the lessons being shared.

\section{THE LANGUAGE OF SCIENCE}

Despite our realization that medicine is not entirely human biology, we do have a staunch belief that the language of science is essential to the practice of medicine and the teaching of cardiothoracic surgery. A key characteristic of the language of science is precision. In scientific writing and speaking, there is almost always one optimal way to describe a process or condition. Any other way of describing a specific phenomenon would be less accurate. It has been said that scientific communication is not poetry. Without precise words and precise language, precise thinking cannot occur.

Another important principle of the language of science is to understand the difference between making observations and making statements. Those making observations are ready to see or learn something new, but those making statements risk missing these opportunities. We would always prefer the company of those who make observations to the company of those who make statements. Another central tenet of scientific communication is to make things as simple and concise as possible, while still maintaining accuracy.

Another, often overlooked, principle of scientific thinking and communication is the "freedom to doubt." As Richard Feynman, ${ }^{1}$ a Nobel Laureate in Physics, once said, "this freedom to doubt is an important matter in the sciences and, I believe, in other fields. It was a struggle to be permitted to doubt, to be unsure." Although we all have heard the adages about the rapidity of change in currently held principles and tenets, we not infrequently hear colleagues, claiming to be "men (or women) of science," assert that some principle or another nears a fundamental, immutable truth. Some of the phrases uttered by those claiming to be working in the scientific mode that should alert the listener to the need for skepticism (followed by the likely true meaning of the phrases) include

"It is believed that..." (I think this might be true)

"It is generally believed that..." (a couple of others think so, too)

"It is clear that more work is required for a complete understanding..." (I don't understand it at all) 
As an old saying goes, we prefer to align ourselves with those who are searching for the truth and remain wary of those who say they have found it. Thus, we believe that although we must apply scientific principles to our work and must make observations as best we can, we must, at the same time, maintain a healthy skepticism about some of those observations and principles, while using language precisely to define what we think we know as well as what we are not as sure about at any given time.

\section{THE LANGUAGE OF PERFORMANCE}

It has been said that one of the primary objectives of medical school, certainly for the first 2 years, is to teach students the language of medicine. However, once this vocabulary has been at least partially mastered, we need to shift to teaching the language of performance. David Brooks, a contemporary writer and thinker, has reminded us in some of his writings that we use our conscious minds to do, at best, about $20 \%$ of our work, leaving to chance the other $80 \%$, to be done by our unconscious minds. A sports psychology associate of ours, Dr Doug Newburg, has pointed out, however, that conflict arises because the models of how we usually learn to perform do not fit with actual performance. He states that the trick is to align the two: the how with the result; the conscious with the unconscious. He points out that almost no one actually does this. However, almost anyone who is really good, does do it. Thus, we have made note of some aspects of the language of performance in medicine and surgery we have found useful, and which, we hope, help take advantage of both the conscious and the unconscious mind.

The language of leadership is certainly a key part of the language of performance. If the leader of the team does not evince optimism or confidence in the possibility of a good outcome, how can he or she possibly expect the many members of a cardiothoracic team to give their all to the cause? This type of leadership was well-articulated by Denton Cooley ${ }^{2}$ in one of his books on the techniques in cardiac surgery, when he wrote, "To maintain the necessary esprit de corps, the surgeon should provide leadership and commitment to each patient. Only he [or she] can inspire the people involved to give their best efforts, even during moments of impending disaster or final defeat." In a somewhat analogous manner, Vince Lombardi famously said, "the difference between a successful person and others is not a lack of strength, not a lack of knowledge, but a lack of will." Conveying optimism combined with the will to persevere, even in the face of daunting odds, is essential to the optimal performance of ourselves and our teams.

It is essential to recognize that the words we choose to use possess psychometric properties. Jason Warnick, a professor at Arkansas Tech, studied the words used by boxers before their bouts. He found that the following were associated with an increased likelihood of losing: increased grammatical nuances, third-person plural words, impersonal pronouns, the past tense, and words conveying tentativeness. In contrast, he found several patterns of language that were associated with an increased chance of winning a bout: words conveying positive emotions, words focusing on health, and words concentrating on work. ${ }^{3}$

Optimizing the language of performance includes making important grammatical choices in the language used. When telling stories, it is often most effective to use the second person. As Myles Edwin Lee ${ }^{4}$ stated in the introduction to Near Misses in Cardiac Surgery, "in order to convey a sense of the pain and anguish endured by members of the team confronting these near-catastrophes and to challenge the reader to feel that the patient's fate depends on his ability to make correct decisions quickly, the author has presented cases in the second person, present tense." Another grammatical choice we believe is important is the use of the active voice. In The Elements of Style, Strunk and White ${ }^{5}$ noted "we find an overabundance of the passive voice in sentences created by self-protecting entities who use the passive voice to avoid responsibility for actions taken. The passive voice should be used when the actor in the situation is not important." An example of the issue of using the passive voice to which many can relate was one of our residents years ago, who seemed unable to say "I broke the suture" but would rather always say "the suture broke." An extrapolation of this tenet, we believe, especially when formally presenting at Morbidity and Mortality conferences, is that the presenter should use, not only the active voice, but also first person pronouns.

Another important facet of the language of performance is the hierarchy of language. As Atul Gawande ${ }^{6}$ correctly pointed out in some of his recent writings, we must recognize the need to move from "a culture of cowboys to a culture of pit crews." Malcolm Gladwell, ${ }^{7}$ in his book Outliers, reviewed the excessive crash rates, in the past, of planes piloted by Korean air crews. An analysis of these crashes revealed that these crews suffered from the inherent hierarchal structure of the Korean language. Crew members, it was found, had struggled to overcome the hierarchy of their language in stressful situations. Once this was recognized, the language of air travel for the Korean crews became English, a language much less inherently hierarchal. ${ }^{7}$ We would do well to recognize this barrier to optimal performance in our own working environments and seek ways to maximize input from all on our teams. One specific way to start this process of breaking down hierarchal barriers is to name everyone in the room by their first name during the time out that precedes every procedure these days.

A related concept is the preservation of the principles of "respectful argument." As James P. Shannon ${ }^{8}$ wrote in an essay on this subject, "one mark of an educated man is 
his ability to differ without becoming angry, sarcastic, or discourteous. The venerable tradition of respectful argumentation, based on evidence, conducted with courtesy, and leading to the exposition of truth, is a precious part of our heritage." A tool in preserving this tradition has been espoused by Suzette Haden Elgin ${ }^{9}$ in her books, one of which is The Gentle Art of Verbal Self Defense. The strategy she has suggested is to acknowledge that "in order to understand what another person is saying, you must assume it is true and then try to imagine what it could be true of." We find this to be a particularly potent tool in not only maintaining courteous discourse but also optimizing learning and collaboration.

In the book How We Talk Can Change the Way We Work, Robert Kegan and Lisa Lahey ${ }^{10}$ pointed out that many gradually move from a language of commitment to a language of complaint. It has been our observation that 1 step in our educational process at which this change in language seems to occur is in the third year of medical school. However, it can and does occur at many other levels. We believe it is incumbent on us, the teachers and leaders, to recognize this sometimes subtle, often unintended, shift and, at the very least, to nudge the language back toward the language of commitment, with which almost all of us entered our profession. One of our friends is a rock drummer, John Molo. He has a line that we have found useful in this conversation: "I play the drums for free. They pay me to travel." We would all do well to think like this in our own work. Perhaps the right quip for us would be: "We will operate for free. They pay us to do the paperwork."

Malcolm Gladwell, ${ }^{11}$ in an article in The New Yorker titled "The Physical Genius," homed in on a central lesson from Charles Bosk's book titled Forgive and Remember, ${ }^{12}$ when, in describing elite performers, he quoted Bosk as noting that "far more than technical skills or intelligence, what was necessary for success was ... a practical-minded obsession with the possibility and consequence of failure." Although this assertion might seem contradictory to Dr Cooley's belief in the need for optimism, the 2 principles are not at all in conflict. A "practical-minded obsession with the possibility of failure" does not require pessimism. What this obsession does require is the acknowledgement of the possibility of failure, a plan to avoid it, and a plan to deal with and learn from it, should it occur.

It is also apparent that the language of constructive criticism is an essential part of the language of performance. We must optimize the lessons of each experience. We should search for the lessons and not the guilty. Also, we must offer these lessons from our hearts, with grace, dignity, and respect for our trainees. As Abraham Lincoln once said, "He has the right to criticize, who has the heart to help."

We must also be constantly searching for ways to include humor in our feedback, because it is generally disarming and almost always more memorable than the same injunction issued in long-winded, dry discourse, as illustrated in this humorous quip said to have been uttered by Marshall Wyatt Earp: "Fast is fine, but accuracy is everything." We are also reminded of another tenet of effective feedback, summarized by this quotation from Ernest Hemingway: "Everything is your fault if you're any damn good." A leader or teacher should start to offer suggestions by accepting responsibility before giving feedback. A great statement we have heard in this vein is, "I must not have told you exactly what I wanted you to do." We have observed that we might have to give a certain set of instructions many, many times before we arrive at the point at which, when we give some precise instruction, virtually everyone to whom we say those exact words does what we want them to do. There could be an analogy here with Anders Ericsson's observation that 10,000 hours of committed practice are necessary to achieve elite performance. ${ }^{13}$ Perhaps we could state that 10,000 conversations need to occur with each of our trainees before they can attain the mastery of the craft of cardiothoracic surgery that we wish them to attain.

It has been said that the founders of the United States brilliantly "started with human beings and worked backwards" to devise the Constitution. We, as teachers giving feedback, must follow that example, starting with human beings and working backward. Constructive criticism, by definition, is given to correct an action that was not optimal. Thus, we are giving bad news to the learner, who undoubtedly will have hoped that whatever action had been taken, if not optimal, was at least adequate. When the learner hears the unwelcome observation that their performance was not adequate, their first reaction is inevitably an emotional one and that reaction can be characterized as grief. We all have heard of Elisabeth Kubler-Ross's stages of grief (denial and anger, bargaining and depression, followed by acceptance and hope). We as teachers (and our trainees as learners) must acknowledge that these emotions are inevitable, although manageable. One of the most effective lines we have heard to help listeners move expeditiously through these stages of grief is the following disarming, but essentially meaningless, line used by one of our mentors: "If I've done that once, I've done it a hundred times." It is hard not to be ready for suggestions with that prelude.

Perhaps these thoughts about the language of performance in the realm of teaching and learning cardiothoracic surgery can be summarized by something Albert Einstein said about a liberal arts education: "The value of an education ... is not the learning of many facts, but the training of the mind to think of something that cannot be learned from textbooks" or by a well-known assertion by the famous medical educator, Tinsley Harrison, who was known to say "I am not here to teach you facts. I am here to teach you how to think."

\section{THE LANGUAGE OF MEMORY}

We believe that we can make the knowledge we must impart most memorable by the telling of stories, complete 
with humor, anecdotes, pithy sayings, and enthusiasm. As Drew Westen wrote in the New York Times a few years ago, "the stories our leaders tell us matter, probably almost as much as the stories our parents tell us as children, because they orient us to what is, what could be, and what should be; to the world views they hold and the values they hold sacred... . Stories were the primary method by which our ancestors transmitted knowledge and values." 14 The famous Southern writer, Flannery O'Connor, added to this concept in one of her assertions about story telling when she said, "There is a certain embarrassment about being a storyteller in these times when stories are considered not quite as satisfying as statements, and statements not quite as satisfying as statistics. However, in the long run, a people is known, not by its statements or its statistics, but by the stories it tells."

As Jerry Lucas and Harry Lorayne ${ }^{15}$ wrote in The Memory Book, "colorful language is memorable language." Another way of looking at creating memory was outlined by Leonard Schlain ${ }^{16}$ in his book The Alphabet and the Goddess, in which he says that, for much of our existence as humans, we functioned more as "right brain dominant beings" than as "left brain dominant beings." Furthermore, he suggested that perhaps the era of the dominance of the left brain could be coming to an end as we now have more access to images and stories and can, thus, revert back to a more "natural" state of learning. ${ }^{16}$

Also, who among us can disagree with Pat Conroy's "great teacher theory" that he outlined in The Lords of Discipline ${ }^{17}$ Conroy $^{17}$ wrote: "It was the cornerstone of the theory that great teachers had great personalities and the greatest teachers had outrageous personalities. I did not like decorum or rectitude in a classroom. I preferred a highly oxygenated atmosphere, a climate of intemperance, rhetoric, and feverish melodrama. And I wanted my teachers to make me smart... . Bad teachers do not touch me; the great ones never leave me. They ride with me during all my days, and I pass on to others what they have imparted to me." Admittedly, these days we must be thoughtful about how intemperate, melodramatic, and colorful we choose to be; however, no doubt exists that none among us wants to be known, as one of our teachers was, as "shifting dullness!"

In addition to learning best from colorful, passionate teachers, we also learn best "from people that we love," as noted by a popular writer in a recent interview. A recent Thoracic Surgery Residents Association survey found that the most important characteristic of a good thoracic surgery training environment was one that was "not malignant." As Dr Kent Trinkle, the former chief of cardiothoracic surgery at the University of Texas at San Antonio, once said, "the only reason to have residents is that you want to teach. First you have to give a damn, second you have to show it."
We believe that we should all be trying to create, as Thomas Jefferson did when he designed the University of Virginia, an "academical village." Although this term might seem archaic, the concept certainly is not. Jefferson's vision of this "village" revolved around the idea that a great deal of the real education that occurs in any environment occurs in the interstices of the system-after hours, at meal time, from peers, in informal conversations. As Wilder Penfield once said, "what a great teacher does is to make it possible for his students to share with him his own enthusiasm in the pursuit of knowledge. Learning can hardly be prevented after that." Perhaps one of the best environments known to our discipline of cardiothoracic surgery was that created by Dr Norman Shumway during his tenure at Stanford. One of his guiding principles was that "the hardest part of heart surgery is getting to do it." He fancied himself as "the world's best first assistant," creating a climate in which many innovations in our field were developed and many fine teaching surgeons were trained. Some of these principles were also outlined by Dr Frank Spencer ${ }^{18}$ in his Gibbon Lecture at one of the American College of Surgeons meetings in the late 1970s, when he noted that "effective teaching blends intellectual and emotional factors to stimulate the student. Developing an emotional response in the audience is important because a fact associated with emotion is retained much better than without emotion."

Another principle of effectively transmitting knowledge and wisdom to consider is one's tone of voice. Wendy Levinson at the University of Toronto has for years studied the tone of voice used by physicians in talking with patients and found very strong correlations between the tone of voice and the likelihood of being sued. As Levinson and colleagues ${ }^{19}$ pointed out: "the surgeon communicates a wealth of information by means of minimal cues that can have important consequences. [Our] data suggest that surgeons' tone of voice in communication might be one key factor in providing satisfactory care...." We were told of an analogous story that involved concerns by Navy pilots on an aircraft carrier with the "Landing School Officers," whose job it is to "talk the pilots down" onto the flight deck when landing their planes. After lengthy discussion, it turned out that all the pilots agreed that, although all the Landing School Officers seemed equally capable, the problem was that the tone of voice some of them used was considered distracting or even disruptive to the pilots. It does not require much imagination to make the analogy to teachers of cardiac surgery talking their protégés through complicated operations. The tone of voice we use in our guiding and teaching in the operating room is surely just as important, not only to the optimal performance of our residents, but also, in the larger sense, to the outcomes of the patients we care for together. 
A discussion such as this about the power of language and effective teaching would be incomplete without turning to the need not only to talk to our residents and students but also to talk with them. We need to start conversations and to keep these conversations going-on rounds, in conferences, and while operating, as well as in the informal moments in between. We learned, somewhat belatedly, from some of our trainees that some of their favorite times were the most informal ones, some of which they had labeled as "Dr So \& So, Unplugged." We all need to search continuously for the words, phrases, and even the "languages" needed to express accurately and memorably what we need to convey to our trainees.

Many overlaps exist between the art of healing and the art of teaching, just as some of these quotations and stories suggest. Many will be familiar with the project of preserving some of the folk history of the people of Appalachia called "The Foxfire Project." In one of the monographs in that series, those gathering information for the project sought out information on the faith healers of the area. What they wrote about these people can and should apply to all of us who fancy ourselves healers and, especially, those of us who are both healers and teachers. They wrote of the faith healers they learned about that these healers were "quiet, simple, strong, and sure. They worked with neighbors individually, when asked to help, and they responded as a gesture of friendship and concern." 20 We are not necessarily saying that the ideal teachers of cardiothoracic surgery fit that description in every way; however, we would suggest that the lessons we want to transmit will most likely be heard and learned optimally when those lessons are "quiet, simple, strong, and sure" and when they are offered with "friendship and concern."

\section{CONCLUSIONS}

So, lying there I knew for the first time the old teacher's frustrations. Just as you cut a little path in the wilderness, you look up and they're gone and you haven't even told them the most important thing. Which assumes, of course, that you know it.

\section{-Reynolds Price, ${ }^{21}$ The Tongues of Angels}

We all start out knowing magic. We are born with whirlwinds, forest fires, and comets inside of us. We are born able to sing to birds and read the clouds and see our destiny in grains of sand. But, then we get the magic educated right out of our souls. We get it churched out, spanked out, washed out, and combed out. We get put on the straight and narrow and told to be responsible. Told to act our age. Told to grow up for God's sake...

\section{-Robert McCammon, ${ }^{22}$ Boy's Life}

We believe in the power of language to inspire, to teach, and to heal. We believe that we, the teachers of our craft, must be connoisseurs of language, in all its forms and in all its modes. There is usually one best way to say something, considering both precision and effectiveness. If what we are saying is not working, we need to change what we say or how we say it. Our trainees come to us as elite performers, virtually all with a certain magic about them. Some are better at some things, some at others. They all deserve to be, and most will thrive when they are, treated with dignity, trust, patience, and, when the timing is appropriate, independence. In many different and important ways, the way we talk will define how effectively we teach our craft.

\section{References}

1. Feynman RP. The uncertainty of science. In: The Meaning of It All, Thoughts of a Citizen Scientist. New York: Perseus Books; 1998.

2. Cooley DA. Techniques in Cardiac Surgery. 2nd ed. Philadelphia: WB Saunders; 1984.

3. Warnick JE, Warnick K. Specifications of variables predictive in the sport of boxing. Percept Mot Skills. 2007;105:153-8.

4. Lee ME. Near Misses in Cardiac Surgery. Auckland: Reed Publishing; 2008.

5. Strunk W, White EB. The Elements of Style. 3rd ed. Needham, MA: Allyn \& Bacon; 1995.

6. Gawande A. Cowboys and pit crews. The New Yorker. May 26, 2011. Available at: www.newyorker.com/online/blogs/comment/2011/05/atul-gawande-harvardmedical-school-commencement-address.html. Accessed May 1, 2013.

7. Gladwell MT. Outliers: The Story of Success. New York: Little, Brown; 2008.

8. Shannon JP. The tradition of respectful argument. In: Varco DL, Delaney JP, eds. Controversy in Surgery. Philadelphia: WB Saunders; 1976.

9. Elgin SH. The Gentle Art of Verbal Self-Defense. New York: Dorset House Publishing; 1985.

10. Kegan R, Lahey LL. How We Talk Can Change the Way We Work. San Francisco: Jossey-Bass; 2001.

11. Gladwell MT. The physical genius. The New Yorker. August 2, 1999.

12. Bosk CL. Forgive \& Remember: Managing Medial Failure. 2nd ed. Chicago: University of Chicago Press; 2003.

13. Ericsson KA, Krampe RT, Tesch-Romer C. The role of deliberate practice in the acquisition of expert performance. Psychological Rev. 1993;100:363-406.

14. Westen D. What Happened to Obama? New York Times Sunday Review. August 6 2011.

15. Lucas JR, Lorayne H. The Memory Book. 2nd ed. New York: Hippocene Books; 1974.

16. Schlain L. The Alphabet and the Goddess. New York: Viking; 1998.

17. Conroy P. The Lords of Discipline. Atlanta: Old NY Book Shop Press; 1991.

18. Spencer FC. Competence and compassion, the John H. Gibbon Lecture at the American College of Surgeons. Bull Am Coll Surg. November 1979:15-22.

19. Ambady N, La Plante D, Nguyen T, Rosenthal R, Chaumeton N Levinson W. Surgeons' tone of voice: a clue to malpractice history. Surgery. 2002; $132: 5-9$.

20. Wigginton BE. Faith healing. In: The Foxfire Book. 1st ed. New York: Anchor Books; 1972.

21. Price ER. The Tongues of Angels. New York: Scribner; 1990.

22. McCammon RR. Boy's Life. New York: Simon \& Schuster; 1992. 